\title{
Migración y transculturación en Europa en el siglo XXI
}

\author{
Armando Gnisci \\ Università La Sapienza di Roma \\ Traducción del italiano: María Luisa Ferraris ${ }^{\bullet}$ \\ Universidad Nacional del Litoral
}

Los demógrafos contemporáneos han elaborado estadísticas que anuncian para fines del siglo XXI una mayoría de mestizos con respecto a los autóctonos en las poblaciones de las naciones de la Unión Europea. Al mismo tiempo, los intelectuales italianos manifiestan

\begin{abstract}
la desorientación que nos ha invadido, a los europeos, frente a los cambios de escena que han transformado muchos aspectos de nuestra vida cotidiana en problemas de elevada y plural complejidad: la humanidad cambia de colores a nuestro alrededor, nos mezcla a los recién llegados que tienen aspecto, hábitos, comida y lenguas diversas. (Bosetti, 2014:7)
\end{abstract}

La situación actual de la Unión Europea y del «espíritu» europeo es una escena ciega y perpleja frente a la gran transformación antropológica e histórica de nuestro tiempo. ¿Qué hacer para que este siglo en el que todos vivimos, pueda convertirse verdaderamente en el tiempo del cambio gentil hacia la concordia del hombre? En el 2014, respondo: nada. Y sin embargo este es el desafío de la humanidad europea en nuestro tiempo y aquellos de nosotros que nos preocupamos del presente-futuro debemos pronunciar esta condición transformadora y animarla con una cosmovisión utópica: aquella que llamo la «Vía de la Transculturación y de la Gentileza» (Gnisci, 2013).

«Utopía» para nosotros significa proyectar un cambio mediante el deseo azaroso de un lugar mejor donde vivir todos juntos. Los lugares donde llevar el deseo y el proyecto de convivencia de millones de seres humanos en migración por todas las civilizaciones, son hoy Europa centro-occidental, la Unión Europea, los Estados Unidos con Canadá, los dos noroestes de la Tierra. Pero la llamada «integración» que los italianos ofrecemos a los inmigrantes es inhóspita, inadecuada y decadente,

\footnotetext{
- Profesora en Letras y Docente de Lengua Italiana. Ex catedrática en la Universidad Católica de Santa Fe y la Universidad Nacional del Litoral. Integra el Centro de Estudios Comparados, el Portal de la Memoria Gringa de la UNL y las Comisiones Directivas del Centro Piemontés de Santa Fe, de la Asociación Civil de Mujeres Piemontesas de la Argentina y de la Asociación Santafesina de Escritores.

Diploma del Circolo dei Cavalieri de Argentina al Ciudadano Italoargentino distinguido (2016) y Premio Piemontés Nacional otorgado por FAPA (2017). Obras publicadas: El malón y otros relatos. II malón ed altri brevi racconti, en edición bilingüe (Dunken, 2015) y Árbol de lluvia (Dunken, 2017).
} 
o mejor, una palabra vacía y una escucha blindada que, en cambio, debería producir una relación mutua llena de fervor, no solo programando la justa integración de los migrantes a nuestra civilización, sino también aprendiendo a reunir nuestra integración a su proyecto de "esperanza». Una nueva y escandalosa condición humana para construir juntos un lugar y un modo mejor de vivir todos juntos: la mitad es la salud social y general compartida en la coevolución transcultural. La posibilidad de instaurar un proyecto recíproco y positivo que, sin embargo, hoy naufraga en las escolleras de nuestro desinterés sordo y egoísta y en la debilidad de los extranjeros, que no llegan con velas, caballos y cañones, como los conquistadores del siglo XVI al Nuevo Mundo. Los migrantes encuentran europeos «unidos» pero sin proyectos utópicos.

La transculturación no es una teoría ni una empresa científica ni una filosofía y menos una ideología, es más bien una cosmovisión poética, ética y política de la acción que nace y opera en la conciencia crítica de formar parte de un movimiento mundial transcultural. La transculturación es una acción que pronuncia, predica y experimenta una transformación antropológica activa y comunitaria a través de una acción justa para cambiar los perfiles de las civilizaciones y de las personas, de las migraciones planetarias, de las descolonizaciones, de las creolizaciones ${ }^{1}$ y de la mundialización de las mentes y de las vidas en nuestro tiempo.

La concepción de una transculturación autocrítica de europeos y migrantes juntos me ha llevado a "pensar con el mundo" entero de la modernidad. Los grados de la cosmovisión son tres momentos cruciales interconectados en espiral: la «descolonización», por nosotros mismos, por nuestra identidad europea de colonizadores y civilizadores - como escribe Sartre introduciendo el libro de Frantz Fanon en 1961, Los perjudicados de la tierra—; la «creolización» de nuestras vidas y la «mundialización» de nuestras mentes y de nuestro mejor espíritu europeo, si aún existe. El todo compartido con los migrantes y sus proyectos, que nuestra nomenclatura dominante define «económicos». Pero estas tres formas críticas y vitales, poéticas y éticas, políticas y cooperantes de la transculturación, no pertenecen solo a los europeos sino a la modernidad global entera que ha visto a los europeos descubrir «todos los mundos al mundo" (Luiz de Camòes) y todos los mundos agredidos y devastados por nuestro fervor feroz. Este es el nudo, antiguo y moderno al mismo tiempo, de la transculturación europea después de cinco siglos de colonialismo y de humillación de los pueblos que ahora vienen por nosotros sin venganza: albaneses y somalíes, rumanos y chinos.

La historia moderna fue inventada y utilizada por los europeos para agredir al mundo. Y es también la historia de la doble combinación de los fenómenos coloniales y explotadores de los europeos sobre los extraeuropeos en todo el mundo, en una guerra mundial jamás finalizada: por una parte, la descolonización-creolización-mundialización de las civilizaciones de todo el mundo modernizado por nosotros, conquistado y ordenado según los modelos de nuestra audaz civilización del siglo XVI. Y por otra, nuestra descolonización, a la que llegamos últimos, hoy, mientras el mundo se descoloniza de nosotros desde hace al menos dos siglos. Pero la corteza del colonizador que está en nosotros — que deberemos iluminar, dice Dante y excoriar, dice Sartre - nos envía signos y deberes de transculturación crítica. Porque estamos perdidos y ciegos, oscurecidos y opacos en el camino del siglo XXI.

Concebí la idea de la doble identidad de la transculturación moderna europea después de haber pensado que el mandato transcultural específico del tiempo en 
el que vivimos es el de actuar éticamente sobre nosotros mismos europeos, entrando en el camino de las tres formas vitales unidas de la transculturación. Después de esta concepción, comprendí que las tres formas vitales, si bien no solo ellas, de la transculturación mundial de todas las civilizaciones modernas son las mismas al revés de aquellas provocadas por nosotros en la conquista y el dominio de las naciones indígenas del mundo, que activaron la resistencia y el dolor, primero, y la superación después. Especialmente en el Caribe y en América Latina. Estas grandes áreas creolizadas del mundo resultan hoy mucho más avanzadas en el camino que nos lleva juntos en vistas a una civilización humana general de las diversidades en la concordia. En el siglo XXI podemos comenzar a considerar esta "visión» como nuestra carga en común con todos los otros y diferentes de todos los otros no europeos, porque dimos a la modernidad un destino violento y todavía antiguo.

Podemos decir que todas las civilizaciones se descolonizan de nosotros desde hace muchísimos años [si no de nosotros, ¿̇e quién?] mientras los europeos occidentales debemos descolonizarnos de nosotros mismos, si no es ahora, ¿cuándo?

Afortunadamente hoy estamos juntos en la coevolución-transculturación con nuestros excolonizados. En efecto, hoy sucede que no estamos más solos en casa. Estamos en una gran mutación transcultural y una nueva Europa está en camino, como sucedió al final del Imperio Romano. La creolización, a su vez, toca todas las civilizaciones, excepto el mundo árabe y, de otro modo, Japón y China.

La mundialización es el camino común y general que va contra la globalización económica que representa hoy el mundo actual como el paraíso del capitalismo desenfrenado y la pesadilla para el $90 \%$ de los seres humanos que no forman parte de la globalización de los negocios, pero la padecen, sin poder entenderlo. La mundialización es el vuelco anticolonialista de la globalización. Ella nos educa, pero no en la escuela, a "pensar con el mundo».

Sostengo que la civilización mundial más avanzada en el camino de la transculturación es la del Caribe y Latinoamérica, unidas, Nuestra América de José Martí, y aquella transcultural de Fernando Ortiz, ambos cubanos. A los europeos nos parecen un montón de islas y de naciones o semi-continentes de derivación lingüística y cultural europea y de segunda clase o tercer mundo, subdesarrollados. Nuestra ignorancia nos lleva a ver a estas naciones así, mientras ellas se han transformado en la vanguardia justa de un presente y de un futuro post-europeo y neo-humanista. Esta civilización binaria (archipielágica y continental) ha ejecutado la liberación armada y la independencia de los europeos como descolonización cultural desde hace 200 años. Ella es mucho más profunda y civil que la «revolución» de los Estados Unidos - una historia de colonos que realizan negocios y agreden al mundo, habiendo aprendido mucho de los ingleses, como escribe Kipling en la Oda de La carga del hombre blanco en 1898.

Nuestra América — con el acento agudo post-español sobre la "é»— produce desde hace doscientos años una gran creolización a través de la fusión —si bien difícil- de tres civilizaciones: indígenas, europeas y africanas. Nuestra América es ultra-europea y su cosmovisión (otro calco formado del espańol) neo-humanista se basa en la defensa de la madre naturaleza y el rescate de los indígenas, en una nueva civilización archipielágica y continental que se apoya en la transculturación y el mejoramiento progresivo del perfil del ser humano completo. Es un proyecto utópico y transcultural en camino. El Caribe es un lugar creativo, poético y activo de la creolización, así como de la mundialización. 
Cuando los europeos conquistamos el Mundus Novus estábamos, sin saberlo, dominados por la voluntad de poder en el encuentro con las otras partes separadas del género humano. Y elegimos, ya convencidos y plenos del principio de dominio, la violencia y la forma civil-(incivil) de nuestra superioridad autoproclamada, en lugar de fundar y proponer una civilización humana general de la diversidad en la concordia. Esta «elección extrema» de la Europa cristiana es precursora de la "Jihad» islámica moderna, hoy solo concebible y visible enteramente pero no definitivamente. Es justamente este el conocimiento tremendo y necesario del nuevo siglo. Nuestro «historicismo transcultural» puede hoy cargar sobre los hombros de Europa la plena responsabilidad de toda la modernidad. ¿Cómo piensa el historicismo del siglo XXI? No tenemos autoridad a quien dirigirnos para "ver y pensar» en profundidad, como hizo Montaigne, mostrando la duda de que el alcance del gran descubrimiento y del encuentro entre europeos y «caníbales» hubiese sido mejor si hubiese sucedido con Alejandro Magno y/o los romanos. En el siglo XXI Alejandro Magno y César Augusto forman parte de las historias superadas y ya muertas desde el siglo XIX. Nosotros pertenecemos, en cambio, a la entera catastrófica modernidad, que dura desde hace cinco siglos de agresión mundial infinita.

Nuestra cosmovisión se enriquece con la consideración radical de la concepción de la civilización europea que liga la modernidad con el nacimiento mismo de Europa en el siglo octavo de la Era Vulgar o de las Lenguas Romances. Así como a fines del Imperio Romano de Occidente los pueblos invasores del Norte y del Este de Eurasia fundaron Europa junto a los latinos y otros pueblos sometidos, hoy las personas y los pueblos de la Gran Migración del Sur y del Este del mundo llevan un nuevo pensamiento-acción a Europa. Los así llamados «bárbaros» actuaron con las guerras y las devastaciones y luego con la transculturación colonial, los segundos parecen actuar con la propuesta, aún no clara pero formidable, de una transculturación dictada por un proyecto utópico mutuo. Es desde allí, desde este nudo histórico en acción, que podemos comenzar a pensar, los europeos, una civilización transcultural compartida con quien viene a nuestro encuentro para vivir entre nosotros. Europa nace de la catástrofe de la estructura del Imperio Romano, cuando los latinos crearon una nueva civilización mestiza y "creola» con los invasores germánicos y godos, pero también con bereberes, árabes, turcos y asiáticos, etc. Los reinos romano-barbáricos formaron una nueva civilización de Europa y en 1492 «descubrieron» e invadieron el Mundus Novus (Amerigo Vespucci). Dijimos que esta apertura de la modernidad nos llevó con Nietzsche a reconocernos hacia fines del siglo XIX como los portadores de la «voluntad de poder», suprema y universal, pero hoy, como escribió Nietzsche hace más de un siglo, el europeo es el «Último Hombre», apático y nihilista.

¿Por qué la modernidad y el colonialismo signan el inicio del capitalismo y de la deshumanización global? Sostengo que los europeos atlánticos (Portugal, España, Francia, Holanda, Inglaterra y luego los suecos, rusos, daneses y alemanes y por fin nosotros italianos desde la segunda mitad del siglo XIX en África) invadieron el mundo entero descubriendo que detentaban la superioridad trascendente sobre todas las civilizaciones descubiertas. Esta superioridad en acto se transformó rápidamente en la matriz de una guerra mundial continua, que aún perdura.

La revolución histórica de lo moderno lleva etimológicamente su significado y su valor: la voz del latín tardío «modernus» viene del adverbio modo que significa «ahora», «mientras lo piensas y lo haces» y por ello «en el tiempo justo». Esto ha 
comportado que los blancos occidentales, europeos y norteamericanos, se hayan sentido tan poderosos como para reconocer en sí mismos el poder hacer todo, sin límites, del mundo y de lo humano, desde Auschwitz e Hiroshima y Nagasaki, hasta los gulag soviéticos.

Los europeos exterminaron y alienaron las nuevas civilizaciones desconocidas de América — distinta será la historia de las grandes civilizaciones asiáticas: India, China, Japón - por cinco siglos todavía hoy actúan junto a los Estados Unidos. Nosotros hemos instaurado el Nuevo Mundo con los otros sometidos y Dios así lo ha querido. En el siglo XVI nace el pensamiento crítico y propiamente humanístico de la modernidad europea, con Montaigne, que en el «Prefacio al Lector» de sus Ensayos, afirma que si él hubiese vivido entre los pueblos del Nuevo Mundo se habría podido expresar plenamente sobre sí mismo y mostrarse verdaderamente al desnudo y por entero. Ellos eran más «naturales» que un hombre europeo culto que representase la condición y la vicisitud del sujeto humano: un europeo era menos humano que los «salvajes».

Para definir Europa y su mandato civil respecto al mundo del siglo XXI, comienzo y coloco en el centro la historia del colonialismo europeo, la maravilla extrema y profunda de la modernidad. Ella muestra el carácter prevalente y crucial de la civilización mundial moderna asumido por las naciones atlánticas europeas en la colonización del mundo, desde el Mundus Novus hasta Australia. El núcleo del encuentro como guerra con el hombre de nuestro colonialismo, lleva en sí la aventura del capitalismo naciente y el camino abierto al principio de superioridad racial y de la carga del hombre blanco (Kipling); de civilizar a los medio-bárbarosdiablos (demi-evil, Shakespeare, La Tempestad, 1611, y half-evil, Kipling, Oda La carga del hombre blanco, 1898) y que encontrará su nombre en la «voluntad de poder» de Nietzsche y la definición en El Capital de Marx. De manera particular en el capítulo sobre la «acumulación originaria del capital», Libro I, VII, cap. 24:

El descubrimiento del oro y la plata en América, el exterminio y la reducción a la esclavitud de la población aborigen, sepultada en las minas, la conquista y el saqueo de las Indias Orientales, la transformación de África en una reserva de caza de pieles negras, son los signos que distinguen la aurora de la era de la producción capitalista. Estos procedimientos idílicos son momentos fundamentales de la acumulación original. Pisándole los talones viene la guerra comercial de las naciones europeas, con el orbe terráqueo como teatro. La guerra comercial se abre con la separación de los Países Bajos de España, asume proporciones gigantescas en la guerra antijacobina de Inglaterra y continúa todavía en las guerras del opio contra China, etc. Este es «el sistema colonial», «la violencia más brutal» del hombre sobre el hombre ejercida por la «civilización occidental» sobre el mundo entero (Marx, 1974:813 y ss.).

El poeta y primer Presidente de Angola, Antonio Agostinho Neto, evidencia el impacto de la civilización occidental sobre las africanas en un poema breve y sorprendente:

\footnotetext{
Chapas clavadas sobre vigas

plantadas en la tierra

hacen la casa

los trapos completan

el último paisaje
} 


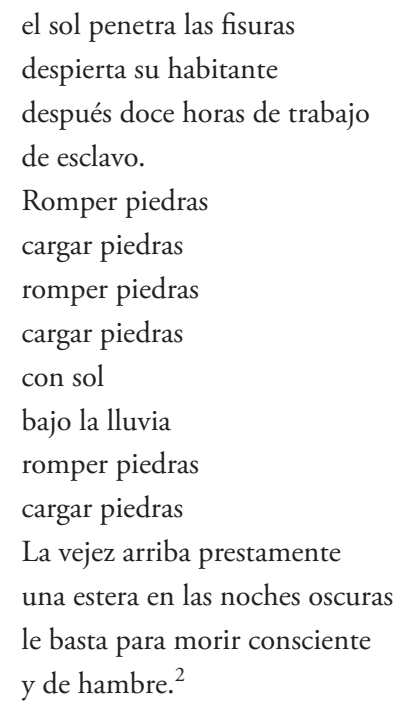

En la Europa de hoy la visión antigua y moderna es puesta en crisis por una invasión humana proveniente de todos los ángulos del mundo, no bárbara ni militar ni mercantil: la Gran Migración. ¿Qué llevan consigo los migrantes económicos en Europa? La carga del migrante es la esperanza de vivir mejor llevando lo mejor de su vitalidad a nuestro mundo viejo y lleno de gente, para insertarse — en lugar de «integrarse»— en la civilización moderna europea de manera creativa, con un proyecto de vida mejor que nos alcanza también. Esta oferta altruista nos obliga a encontrarnos y cooperar en una partnership del convivir y co-evolucionar descolonizándonos, creolizándonos y mundializándonos, juntos.

Este es el proyecto utópico de los migrantes al que respondemos con sordera, tolerancia, caridad, asistencia e «integración». Esta es la utopía de la civilización humana general de la diversidad en concordia.

Para caminar pensando con el mundo del siglo XXI y para aprender a legar algo al mundo después de haberlo devastado por cinco siglos, Europa debe avanzar con el proyecto civil de la transculturación. Que no sea nuestra "civilización moderna». El fruto será la posible Concordia del siglo XXI. Creo que la cosmovisión que trata la relación entre transculturación y migración en el siglo XXI, poniendo en juego el nudo del colonialismo moderno y el feroz pero formidable origen de Europa, nos permite distinguir y comprender más a fondo los fenómenos sociales importantes de nuestro nuevo siglo.

Propongo como ejemplo perturbador la nueva emigración juvenil europea. Es la que podemos definir "el rechazo de vivir en Europa" por parte de creolos, hijos de padres emigrados en Europa viniendo de la gran área mundial de naciones árabes y musulmanas, pero también de jóvenes europeos convertidos al Islam. Estas personas eligen la fuga de Europa para enrolarse en el anticolonialismo combatiente y terrorista de las zonas medio-orientales de Eurasia donde el fundamentalismo islámico armado destruye ciudades y civilizaciones, mata musulmanes, europeos y norteamericanos. El fundamentalismo islámico y la rebelión anti-occidental de jóvenes migrantes de Occidente a Medio Oriente nos advierte que ellos eligen como cosmovisión la memoria de las humillaciones de cinco siglos de colonialismo occidental y del dominio euro-americano y la venganza. La fuga clandestina desde 
Europa de los «anti-creolos» de origen árabe para transformarse en justicieros y salvadores de las patrias islámicas, es un enrolamiento en las filas del terror, no loco, sino heredero del odio anticolonial irrevocable. Pero, además de liberar las tierras del Islam de los occidentales y de transformar la humillación secular hacia ellos, nos combaten y aterrorizan, en Oriente y en nuestra casa, en Europa, los Estados Unidos y África. Estos jóvenes se vuelcan a la Jihad coránica, entendida como batalla armada y última contra el enemigo de siempre, Occidente, que todavía es colonialista.

Creo, finalmente que la coeducación transcultural entre europeos y migrantes, como sucedió cuando Europa fue creada por los bárbaros con los latinos mediterráneos, debería inspirar a los políticos y a los intelectuales europeos para re-pensar y re-formar los contenidos de las curricula humanistas y civiles de la escuela pública y de las universidades. El nuevo método y la nueva civilización creolizada deben tender a estudiar y a "pensar con el mundo", como dice Édouard Glissant, partiendo de la modernidad europea para pasar a lo antiguo y al futuro que se va formando en nuestro siglo que avanza.

Imagino y espero que desde hoy en Europa los migrantes sean considerados como nuestros mejores amigos.

\section{Notas}

${ }^{1}$ En el seno de las teorizaciones de Edouard Glissant (novelista, poeta y ensayista francés nacido en la Martinica) créolization enuncia el proceso de formación de las sociedades créoles, producto del contacto de varias culturas o al menos de varios elementos de culturas distintas, con la resultante de un nuevo dato, totalmente imprevisible, en relación a la suma o a la simple síntesis de esos elementos. Así concebida, la créolisation designa todo lo «imprevisible» nacido de esta elaboración de entidades culturales inéditas a partir de aportes diversos y se diferencia del mestizaje por sus condiciones de desarrollo y expansión. En los estudios post-coloniales y de literatura comparada de las últimas décadas ha ido un concepto fuertemente asociado a los parámetros de aislamiento y migraciones. Créole: Persona de ascendencia europea, en particular francesa, nacida en una de las antiguas colonias centroamericanas, en particular las Antillas. Las lenguas créoles son las que provienen del contacto con las lenguas de la colonización, las indígenas y las importadas de África.

${ }^{2}$ Neto (2001:50-51). El título del breve poema de Neto es «Civilizacion

Occidental». 
Migración y transculturación en Europa en el siglo XXI · A. Gnisci

\section{Referencias bibliográficas}

Bosetti, G. (2014). Prefazione. En AA.VV., Omnia mutantur. La scoperta filosofica del pluralismo culturale. Marsilio.

Gnisci, A. (2013). Via della Transculturazione e della Gentilezza. Ensemble. Marx, K. y Engels, F. (1974). Opere complete. Editori riuniti.

Neto, A.A. (2001). Speranza sacra [traducción italiana Pedro Francisco Miguel]. Il Lavoro.

\section{Gnisci, Armando}

«Migración y transculturación en Europa en el siglo XXI». El hilo de la fábula. Revista anual del Centro de Estudios Comparados (20), 137-144. 